\title{
锂硒电池正极材料设计
}

庄林

武汉大学化学与分子科学学院, 武汉 430072

\section{Design of Cathode Materials for Lithium-Selenium Batteries}

\section{ZHUANG Lin}

College of Chemistry and Molecular Sciences, Wuhan University, Wuhan 430072, P. R. China.

Email: lzhuang@whu.edu.cn.

Published online: December 4, 2018.

随着移动电子设备和新能源汽车的飞速发 展, 可充电池技术越来越受到重视。而目前应用最 为广泛的锂离子电池, 其能量密度仍然较低( 200 $\mathrm{Wh} \cdot \mathrm{kg}^{-1}$ ), 且安全性较差。开发新型电池体系及电 极材料越来越受到关注。

锂硒电池作为一种高体积能量密度的新型电 池体系, 成为近年来研究的热点。锂硒电池具有高 达 $3253 \mathrm{mAh} \cdot \mathrm{cm}^{-3}$ 理论体积比容量 ${ }^{1}$, 并且硒 $(1 \times$ $\left.10^{-3} \mathrm{~S} \cdot \mathrm{m}^{-1}\right)$ 的电子电导率远高于硫 $\left(5 \times 10^{-28}\right.$ $\mathrm{S} \cdot \mathrm{m}^{-1}$ )。锂硒电池在体积受限的领域(如手机、电动 汽车等)中具有潜在应用价值。

虽然锂硒电池有较高的体积能量密度, 但其 循环寿命和目前商业化的锂离子电池相比还相差 甚远。这主要是由于锂硒电池在充放电循环过程 中存在着类似锂硫电池的穿梭效应 ${ }^{2}$, 即在充放电 过程中, 溶解在电解液中的高聚硒化物会穿过隔 膜扩散到锂负极, 与金属锂发生副反应。这种穿 梭效应导致了锂硒电池较快的容量衰减, 较差的 循环性能和较低的库仑效率 3 。如何设计锂硒电 池正极材料来抑制这种穿梭效应是该领域的研究 热点。

此外, 锂硒电池对于不同的电解液表现出不 同的反应机理。在醚基电解液中, 锂硒电池的锂 化/脱锂过程与锂硫电池中的逐步反应机制几乎相 同, 多硒化物也可溶于醚类电解液 ${ }^{4}$ 。而在碳酸盐 基电解液中, 放电期间硒直接被还原为硒化锂, 可 有效抑制穿梭效应 ${ }^{5}$ 。

锂硒电池的另外一个问题就是锂离子在硒正
极中的扩散速率较低, 导致了硒正极的利用率不 高, 倍率性能较差。众所周知 6,7 , 电极材料中的锂 离子扩散时间 $(T)$ 由其扩散路径长度 $(L)$ 和扩散系 数 $(D)$ 决定 $\left(T=L^{2} / D\right)$ 。在扩散系数很难大幅度提高 的情况下, 要缩短扩散时间, 最好的方法就是缩短 扩散长度。这意味着可以通过减小材料尺寸来缩 短锂离子的扩散时间, 从而提高其反应活性和动 力学。

针对以上问题, 许多研究小组近几年在设计 新型纳米结构硒正极, 选择适配电解液和抑制穿 梭效应方面做了诸多尝试, 取得了显著进展, 有效 提高了锂硒电池的循环寿命和倍率性能。鉴于此 研究领域的重要性, 复旦大学材料科学系周永宁 教授等人针对锂硒电池正极材料的研究现状和进 展进行了综述。

该工作已在物理化学学报上在线发表 (doi: 10.3866/PKU.WHXB201806062) ${ }^{8}$ 。该综述讨 论了锂硒电池的优势和存在的问题, 着重介绍了 硒-碳复合正极材料的研究进展, 从一维、二维和 三维结构的角度，分析了硒基正极材料结构和性 能之间的关系, 最后深入探讨了锂硒电池的反应 机理及其与电解液的相关性, 并展望了锂硒电池 的未来发展方向。该工作对于该研究领域未来的 研究方向具有重要的启发意义。

\section{References}

(1) Zhou, J.; Qian, T.; Xu, N.; Wang, M.; Ni, X.; Liu, X.; Shen, X.; Yan, C. Adv. Mater. 2017, 29, 1701294. doi: 10.1002/adma.201701294 
(2) Abouimrane, A.; Dambournet, D.; Chapman, K. W.; Chupas, P. J.; Weng, W.; Amine, K. J. Am. Chem. Soc. 2012, 134, 4505. doi: $10.1021 / \mathrm{ja} 211766 \mathrm{q}$

(3) Han, K.; Liu, Z.; Shen, J.; Lin, Y.; Dai, F.; Ye, H. Adv. Funct. Mater. 2015, 25, 455. doi: 10.1002/adfm.201402815

(4) Cui, Y.; Abouimrane, A.; Lu, J.; Bolin, T.; Ren, Y.; Weng, W.; Sun, C.; Maroni, V. A.; Heald, S. M.; Amine, K. J. Am. Chem. Soc. 2013, 135, 8047. doi: $10.1021 / \mathrm{ja} 402597 \mathrm{~g}$

(5) Cui, Y.; Abouimrane, A.; Sun, C.; Ren, Y.; Amine, K. Chem.
Commun. 2014, 50, 5576. doi: 10.1039/c4cc00934g

(6) Tang, Y.; Zhang, Y.; Li, W.; Ma, B.; Chen, X. Chem. Soc. Rev. 2015, 44, 5926. doi: $10.1039 / \mathrm{c} 4 \mathrm{cs} 00442 \mathrm{f}$

(7) Vu, A.; Qian, Y.; Stein, A. Adv. Energy Mater. 2012, 2, 1056. doi: 10.1002/aenm. 201200320

(8) Chen, D.; Yue, X.; Li, X.; Wu, X.; Zhou, Y. Acta Phys. -Chim. Sin. 2019,35 (7), 667. [陈东, 岳昕阳, 李璕琭, 吴晓京, 周永宁. 物理 化学学报, 2019, 35 (7), 667.] doi: 10.3866/PKU.WHXB201806062 